\title{
ARTICLE Prevention of diving-induced spinal cord injuries - preliminary results of the first Romanian mass media prophylactic educational intervention
}

\author{
Aurelian Anghelescu ${ }^{1,2}$
}

STUDY DESIGN: The study was an observational study of the seasonal incidence of diving accidents, according to the summer weather pattern and the influence of an educative prophylactic intervention.

OBJECTIVES: The study analyzed the preliminary results of a national project, disseminated on social networking (Facebook) and broadcasted on main national and international Romanian TV channels.

SETTING: The study was conducted at the Neurorehabilitation, Teaching Emergency Hospital 'Bagdasar-Arseni.'

METHODS: The study had a dichotomous design (a retrospective review and a prospective component), and it analyzed the evolution trends of diving accidents, before and after the prophylactic intervention. The retrospective review analyzed 41 diving accidents, registered during 2011-2015. The prospective component focused on cases registered in 2016. Spearman's Rho non-parametric test was used to evaluate the association between two variables (the air temperature and the number of diving accidents).

RESULTS: The study involved 46 males and 1 female, with a mean age (at the time of injury) $26.4 \pm 7.02$ (median 25, mode 23), admitted to rehabilitation in an early post-acute status after surgical intervention. Male youths and young adults $<35$ years old represented $83 \%$ of all cases. During 2011-2015, a monotonic association between the summer climate and the incidence of diving-induced tetraplegia $(R=0.97468 ; P=0.00482)$ was noticed. Analyzing the evolutionary trends of similar cases registered in 2016 , variables did not increase in value together $(R=0.73561 ; P=0.09561)$. In 2016 , the number of diving-induced quadriplegics was reduced on average by $26.8 \%$.

CONCLUSIONS: One year is not enough for a successful, durable educative intervention. It is compulsory to continue, extend and intensively promote this program.

Spinal Cord Series and Cases (2017) 3, 17018; doi:10.1038/scsandc.2017.18; published online 18 May 2017

\section{INTRODUCTION}

Plunging headlong in turbid and/or shallow waters can cause potentially severe vertebrae fractures and traumatic spinal cord injuries, primarily affecting the cervical spine (CSCl). Diving accidents are caused by lack of attention, overexuberant youth behavior and unsupervised summer recreational activities. ${ }^{1,2}$ Careless diving in unverified waters can produce devastating, but preventable accidents ${ }^{3}$ - people aged $15-24$ being at the highest risk. ${ }^{1,2,4}$

Previous epidemiological studies (during the last 35-40 years) described identical demographic characteristics of the target population predisposed to experience diving-induced $\mathrm{CSCl}$. Most victims were males (86-95\%), without pre-existing medical problems, $^{1,4-7}$ Reasons included diving into shallow water and striking their head on the bottom of the pool (sea, river), or hitting a hidden object under turbid water, with resultant cervical fractures. ${ }^{8}$ Most accidents (57\%) occurred at a depth of $<1-1.4 \mathrm{~m}^{4,7}$

In order to reduce the risk, Blitvich et $a l^{9}{ }^{2}$ realized a complex kinematic analysis (angle of plunge, flight distance and velocity at maximum depth) to assess 'low-risk' and 'high-risk' dives, and proposed practical solutions to avoid $\mathrm{SCl}$ in young divers.
The majority of the injuries occurred in the mid to low cervical spinal column (C5-6 vertebrae). ${ }^{1,5,8}$ This is a region susceptible to fractures due to its great biomechanical mobility.

Most victims survive, but this major life-disrupting condition has devastating repercussions on the patient's physical (neurological and functional) status, psychological and social well-being, as well as for the patient's family, who incur immense psychological and financial costs. ${ }^{10}$

The socioeconomic consequences of this drama have an important impact on the health system budget. In the USA, the direct and indirect financial effort for treating a patient surviving $\mathrm{SCl}$ in the first year after injury can reach (depending on the severity) from $\$ 334 \mathrm{~K}$ to 1 million, and each subsequent year represents a budgetary contribution evaluated at $\$ 41-$ to $\$ 178 \mathrm{~K}^{11}$ Care costs over the entire life of a tetraplegic are estimated between 1.8 and 2.7 million USD (http://www.asia-spinalinjury.org/ commi/prevention_facts.php).

Widespread prevention public programs, aimed to raise awareness, to educate and modulate the human behavior are essential to decrease the incidence of these water-related injuries. An effective prophylaxis should be focused on education of the potential target victims, who often associate recreational diving, sport and alcohol ingestion (in $47 \%$ of SCls). ${ }^{7}$ Injury prevention

\footnotetext{
${ }^{1}$ Teaching Emergency Hospital 'Bagdasar-Arseni', Bucharest, Romania and ${ }^{2}$ University of Medicine and Pharmacy 'Carol Davila', Bucharest, Romania. Correspondence: A Anghelescu (aurelian_anghelescu@yahoo.co.uk) 


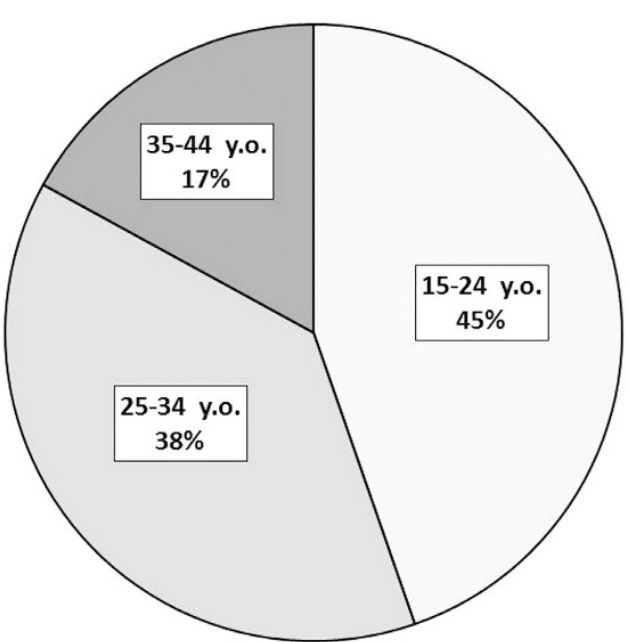

Figure 1. Age (decades) distribution of the entire group of patients with diving-induced CSCl. (y.o., year-old).

initiatives reduced the occurrence of $\mathrm{CSCl}$ associated with diving or other sports 2,12

\section{MATERIALS AND METHODS}

The study had a dichotomous design and focused on the evolutionary trends of diving accidents, before and after a national prophylactic intervention.

The retrospective branch analyzed 41 cases of diving-induced $\mathrm{CSCl}$ (of 173 traumatic quadriplegics, operated and transferred in early post-acute status to rehabilitation) during 2011-2015.

The prospective component studied the results of a prevention public intervention, disseminated through social networking and mass media (main Romanian TV channels), to decrease the incidence of diving accidents (from 1 June to 15 September 2016). Six persons with diving-induced $\mathrm{CSCl}$ (of 71 new traumatic quadriplegics) were admitted to rehabilitation in 2016.

All cases were classified and registered in the database using the diagnosis-related group system. The primary diagnosis was coded G82.31 (flaccid, acute and tetraplegia); the secondary was either W16 (dive or jump into water, causing a traumatic injury) or U54 (plunging into the water from a cliff).

Patients were categorized according to their gender, age, month of injury, vertebral level of injury and ASIA impairment scale (at admission).

The results were analyzed with tools for descriptive statistics (mean, median and mode, s.d. and histogram distribution of the patients). Spearman's Rho non-parametric test was used to measure the strength of association between two variables-the air temperature and the number of diving-induced $\mathrm{CSCl}$.

Meteorological data were collected from the National Meteorological Administration. ${ }^{13,14}$ The climatic characteristics registered in July and August, during 2011-2016, were focused on the maximal and mean values of air temperature $\left(T^{0}\right)$, collected from two southern macroregions of Romania-Oltenia and Muntenia. For statistical processing, the arithmetic averages of the maximal and mean $T^{0}$ were used.

The non-profit educative program of intervention was initiated by TEHBA and the Romanian Spinal Cord Society (RoSCoS) on 1 July 2016. The author posted a letter addressed (mostly) to the teenagers and young people on his Facebook account, a banner and a video clip with the message: 'Do not plunge headlong into murky or shallow waters. Fractures of the neck vertebrae and spinal cord injury cause severe paralysis (tetraplegia) or even death'. Dissemination of medical information was accessible and targeted to a large group of population; the clinical picture of a tetraplegic person was associated with the situation of a wellknown football player and a cinema personality.

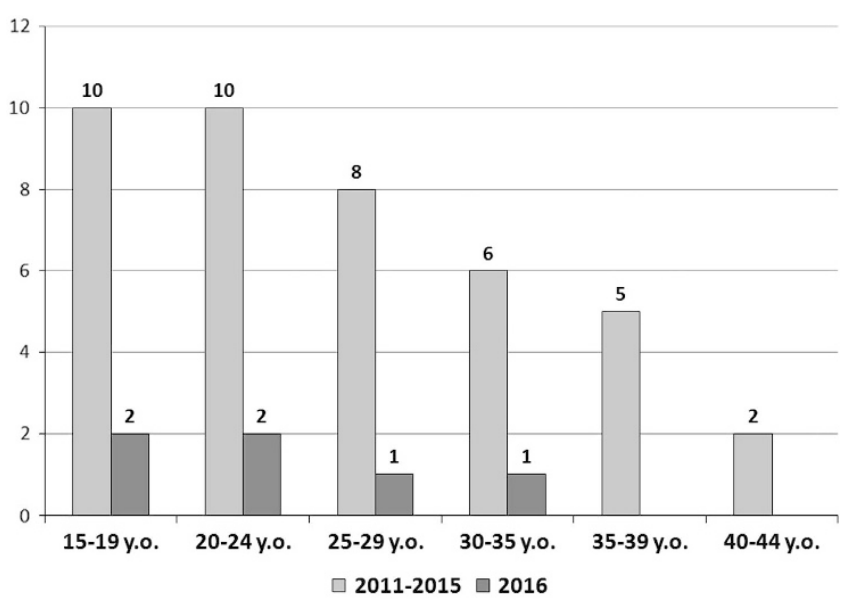

Figure 2. Age at injury and the annual incidence of diving accidents.

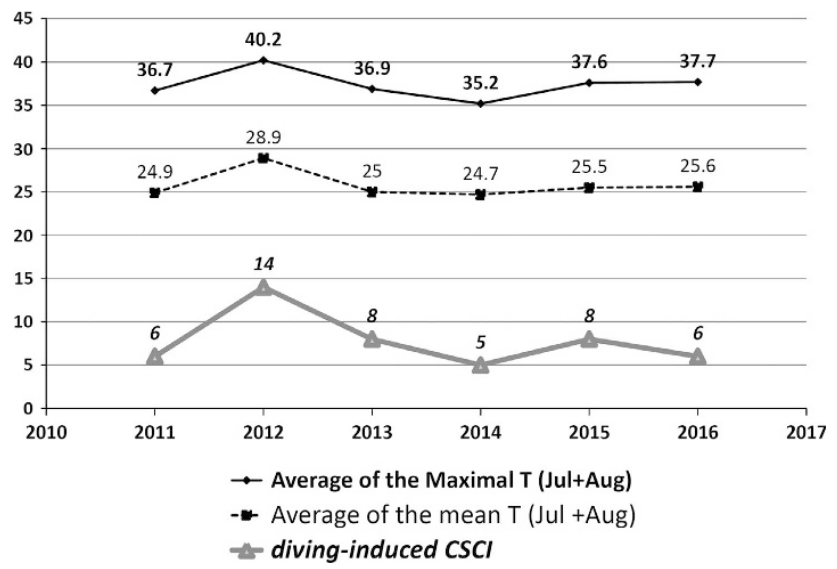

Figure 3. Average values of the summer air temperatures and the incidence of diving-induced $\mathrm{CSCl}$.

The project had the favorable approval of the National Council of the Audiovisual. The National Television (TVR 1, 2, 3 and TVR International) and ProTV Company (broadcasting on large audience TV channels: Home, Home Gold, ProCinema, ProTV, ProTV-International, Ro-MTV, Sport.ro) had an essential role in promoting the educative video clip.

As the project advanced, information was completed on social media with an original poster and video chronicles of three young tetraplegic survivors, who expressed their consent to be filmed and had the goodwill to share their dramatic experience with the target public. The poster was drawn up in collaboration with a very active person in a wheelchair. The scientific educative information was deliberately presented in a gloomy contrast (in a non-offending manner), being psychologically channeled to shock and alert the careless, overexuberant target population.

Our intention was to have the largest access in population, also by phone SMS, but we had no support from the private mobile phone companies.

\section{RESULTS}

The study involved 46 males and 1 female, with a mean age (at the time of injury) $26.4 \pm 7.02$ (median 25 years, mode 23 and a Gaussian distribution), admitted to rehabilitation. Male youths and young adults $<35$ years old represented $83 \%$ of our subjects (Figures 1 and 2).

The neurological status at admission (after surgical decompression and spine stabilization) was as follows: AIS-A (27 subjects; 


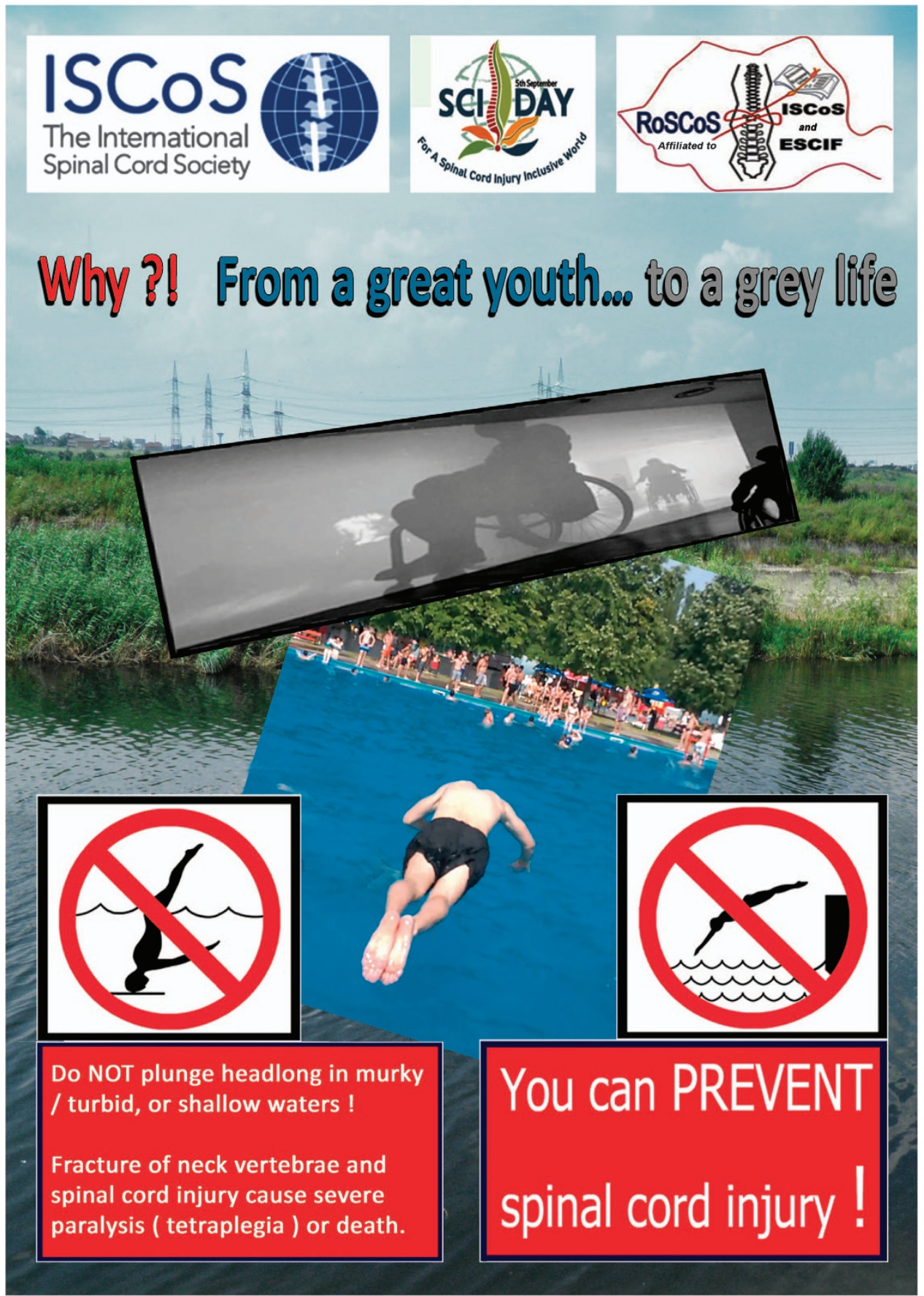

Figure 4. Poster: 'Prevent $\mathrm{CSCl}$ caused by plunging headlong into unsafe/unfamiliar water'.

57.5\%), AIS-B (4; 8.5\%), AIS-C (9; 19.1\%) and AIS-D (7; 14.9\%). The most common neurological motor level was C6 (29 cases; 61.7\%).

\section{DISCUSSION}

In the present study, diving-induced $\mathrm{CSCl}$ represented $19.2 \%$ of 244 traumatic quadriplegics, first time admitted on rehabilitation, after surgical management.

Diving accidents reported in summer can account for $4.7^{15}-6.3 \%$ of all SCls (up to $10.6 \%$ in Brazil, ${ }^{16} 18.2 \%$ in Turkey ${ }^{17}$ or $21 \%$ mentioned by an older study ${ }^{1}$ ); in Romania this etiology was responsible for $7 \%$ of all SCls (in 1994). ${ }^{18}$

From seven metropolitan clinical emergency hospitals in Bucharest, two trauma centers ('TEHBA'-the reference center for $\mathrm{SCl}$ surgical treatment and neurorehabilitation, and 'Floreasca') admitted the most severe patients with central nervous system lesions, mainly (but not exclusively) from two southern macroregions of Romania-Oltenia (consisting of 5 areas, with about 3.903.955 inhabitants) and Muntenia (comprising 15 areas and Bucharest, with about 5.408.609 inhabitants). ${ }^{19}$

A very useful epidemiological approximation of diving-induced $\mathrm{CSCl}$ incidence was reported in a previous Austrian study: 'one person per one million inhabitants per year sustains a spinal cord injury in a diving accident in shallow water'. ${ }^{20}$

During the 'long hot summer' 2016, the number of divinginduced CSCI was reduced on average by $26.8 \%$ ( 6 cases, compared with the annual average of 8.2 patients recorded during 2011-2015). Was the result statistically significant or a mere coincidence? 
The influence of our national intervention was revealed by measuring the strength of association between two variablesthe independent (air $T^{0}$ ) and the dependent ones (number of diving-induced CSCI). During 2011-2015, a monotonic association between the summer climate and the incidence of diving accidents was noticed (Figure 3). Applying the Spearman's Rho non-parametric test, the calculated $R$ was 0.97468 and the two-tailed value of $P$ was 0.00482 . By normal standards, the association between the two mentioned variables was considered statistically significant (the variables increased in value together).

Including and analyzing the evolution trend of the $\mathrm{CSCl}$ registered during the torrid summer 2016, the results neither correlated for the maximal nor for the mean values of temperature ( $R 0.73561$ and $\mathrm{P}$ 0.09561-association not statistically significant). Based on the statistical interpretation, one can assume that reduction of diving accidents in 2016 was probably not a simple coincidence, and support our continuing this educational program.

This study has some objective limitations. One year is not enough for a successful, durable educative intervention. Encouraged by these preliminary findings, we intend to enhance and intensely promote this project during 2017, by increasing broadcasting arrangements and extending cooperation with other $\mathrm{SCl}$ units in Romania.

Epidemiological data in our study, and similar ones reported in the literature, ${ }^{2,7,9}$ indicated that the target population exposed to neck vertebrae fractures and tetraplegia, after careless plunging headlong into shallow, unsafe/unfamiliar waters, were the teens and young male adults. This is the group at risk, potential victims (representing $83 \%$ of our subjects), and the beneficiary of further sustained education interventions, for safe recreational behaviors. A worldwide documented assertion advocates that primary prophylaxis is the real 'cure' for this pathological entity.

Considering the valuable experience of the Canadian project 'Think First-Sport Smart' aimed to prevent $\mathrm{SCl}$ caused by shallow water diving among teenagers in high schools, ${ }^{2}$ we intend to approach the Romanian National Ministry of Education and Scientific Research, and provide an extended educational information package, containing additional medical accessible information (CD, brochures such as the ASIA prevention brochure ${ }^{21}$ ) and qualified scientific explanations, with the proposal to be included in a future scholar curriculum.

Beyond its main prophylactic aim, the project has rendered homage to the initiative of the World Health Organization (WHO) and International Spinal Cord Society (ISCoS) to celebrate the 'Spinal Cord Injury Day' and increase awareness among health authorities and the general population, 'For a Spinal Cord Injury Inclusive World'. Our contribution (poster-Figure 4; Supplementary video) was appreciated; the film was posted on the website http://worldsciday.org/romania_avs.html ('Prevention of SCI AV for General Public 00:15 secs'). ${ }^{22}$

\section{ACKNOWLEDGEMENTS}

The authors thank Professor Dr Mircea Gorgan, Medical Director, Teaching Emergency Hospital 'Bagdasar-Arseni', Bucharest, Romanian National Television (TVR) and ProTV Company for their essential role in promoting the video clip, Professor Dr Harvinder Singh Chhabra for his kind support to our project and RoSCoS,
Dr lonut Octavian Frecea and Mr Octavian Frecea for their technical assistance and contribution to the video clip and poster, and Mr Marius Strat for his contribution to the poster and Dr Marius-Victor Birsan, Department of Climatology, Meteo Romania.

\section{COMPETING INTERESTS}

The author declares no conflict of interest.

\section{REFERENCES}

1 Aito S, D'Andrea M, Werhagen L. Spinal cord injuries due to diving accidents. Spinal Cord 2005; 43: 109-116.

2 Bhide VM, Edmonds VE, Tator $\mathrm{CH}$. Prevention of spinal cord injuries caused by diving: evaluation of the distribution and usage of a diving safety video in high schools. Inj Prev 2000; 6: 154-156.

3 Vlok AJ, Petersen J, Dunn RN, Stander J. Shallow-water spinal injuries, devastating but preventable. S Afr Med J 2010; 100: 682-684.

4 DeVivo M, Sekar P. Prevention of spinal cord injuries that occur in swimming pools. Spinal Cord 1997; 35: 509-515.

5 Chan-Seng E, Perrin FE, Segnarbieux F, Lonjon N. Lésions traumatiques du rachis cervical par accident de plongeon: une étude rétrospective descriptive de 64 patients à 10 ans de recul. Revue de Chirurgie Orthopédique et Traumatologique 2013; 99: 507-508.

6 Tu Y, Liang H-W, Wang Y-H, Kang J-H, Bih L-I, Tang F-T. Survey of spinal cord injuries due to diving accidents in Taiwan. Tw J Phys Med Rehabil 2006; 34: 11-17.

7 Barss $P$, Djerrari H, Leduc BE, Lepage Y, Dionne CE. Risk factors and prevention for spinal cord injury from diving in swimming pools and natural sites in Quebec, Canada: a 44-year study. Accid Anal Prev 2008; 40: 787-797.

8 Green BA, Gabrielsen A, Hall WJ, O'Heir J. Analysis of swimming pool accidents resulting in spinal cord injury. Paraplegia 1980; 18: 94-100.

9 Blitvich JD, McElroy GK, Blanksby BA, Douglas GA. Characteristics of 'low risk' and 'high risk' dives by young adults: risk reduction in spinal cord injury. Spinal Cord 1999; 37: 553-559.

10 Onose G, Anghelescu A. Rehabiliation after spinal cord injury SCI (in Romanian). In: Neurosurgery, vol. 2. Editura Medicala: Bucharest, Romania, 2011, pp 3-109.

11 Wyndaele JJ, Chhabra HS, ISCOS 'Spinal Cord Injury Day' Press release. 2016. Available at: http://www.worldsciday.org., accessed Sept 2016.

12 DeVivo MJ. Epidemiology of traumatic spinal cord injury: trends and future implications. Spinal Cord 2012; 50: 365-372.

13 National Meteorological Administration (INMH). Available at: http://www.meteor omania.ro., accessed Sept 2016

14 National Meteorological Administration (INMH). Available at: http://rp5.md/ Arhiva meteo \%C3\%AEn_Bucure\%C5\%9Fti,_Filaret., accessed Oct 2016.

15 Chen Y, Tang Y, Vogel LC, Devivo MJ. Causes of spinal cord injury. Top Spinal Cord Inj Rehabil 2013; 19: 1-8.

16 Amorim EC, Vetter H, Mascarenhas LB, Gomes EG, Carvalho JB, Gomes JF. Spine trauma due to diving: main features and short-term neurological outcome. Spinal Cord 2011; 49: 206-210.

17 Güzelküçük Ü, Kesikburun S, Demir Y, Aras B, Özyörük E, Yilmaz B et al. Demographic and clinical characteristics of patients with traumatic cervical spinal cord injury: a Turkish hospital-based study. Spinal Cord 2015; 53: 441-445.

18 Soopramanien A. Epidemiology of spinal injuries in Romania. Paraplegia 1994; 32: 715-722.

19 Population of Romania on macro-regions and counties. Available at: http://www.dcnews.ro/recensamant-2011-populatia-romaniei-pe-macroregiuniregiuni-si-judete-vezi-cati-locuitori-are-judetul-tau_351415.html., accessed Oct 2016.

20 Schwarz N, Sim E, Nestinger K. Injuries of the thoracic vertebrae in head-first dive into water. Unfallchirurg 2001; 104: 300-302.

21 ASIA Prevention brochure. Available at: http://asia-spinalinjury.org/wp-content/ uploads/2016/05/Prevention_Brochure_2013_2.pdf., accessed Oct 2016.

22 Romania-SCl Day. Available at: http://worldsciday.org/romania_avs.html., accessed Sept 2016. 